\title{
Derivation of thermodynamic quantities from kinetic measurements
}

\author{
Robin Walsh \\ Department of Chemistry, University of Reading, Whiteknights, P.0. Box 224, \\ Reading RG6 2AD, U.K.
}

\begin{abstract}
Results are presented of both traditional equilibrium and also gas phase kinetic measurements. These results are used to show, (1) that measured enthalpies of formation of the fluorosilanes are probably in error, (2) a $\beta$-silicon substituted alkyl radical is stabilised by $c a 12 \mathrm{~kJ} \mathrm{~mol}^{-1}$ and (3) the simplest divalent silicon species, $\mathrm{SiH}_{2}$, has an enthalpy of formation of $273 \pm 6 \mathrm{~kJ} \mathrm{~mol}^{-1}$, some $30 \mathrm{~kJ} \mathrm{~mol}^{-1}$ higher than earlier estimates.
\end{abstract}

\section{INTRODUCTION}

Traditional methods of determining thermodynamic quantities centre on calorimetry and the study of equilibria (ref. 1,2). These methods are appropriate for pure stable compounds and clean reactions but are not generally possible for reactive species of lower (or higher) valence states than those commonly encountered. An approach which has proved useful for such species is that based on a variant of the equilibrium law, viz. the principle of microscopic reversibility (see e.g. ref. 3). In a reversible process such as

$$
\mathrm{A}+\mathrm{B} \stackrel{\mathrm{f}}{\stackrel{\mathrm{r}}{\rightleftarrows}} \mathrm{C}+\mathrm{D}
$$

the equilibrium constant $K$ is obtained as the ratio of forward and reverse state constants $k_{f} / k$. This procedure is valid provided the elementary processes can be clearly identified and their rate constants measured under identical conditions (with the proper maintenance of a Boltzmann distribution over internal states for all species). Measurements of rate constants can therefore be used to obtain useful thermodynamic information on a variety of interesting, reactive species.

In this article, I describe some selected results of the application of both conventional equilibrium and rate studies to the determination of thermodynamic quantities, particularly enthalpies of formation for a variety of silicon-containing molecules. Since a substantial part of our studies has already been published (ref. 4,5,6) the emphasis here is on recent findings and remaining uncertainties.

\section{EQUILIBRIUM MEASUREMENTS}

We have applied the equilibrium method to the determination of reliable $\Delta H_{\mathrm{f}}^{\ominus}$ values for the methylsilanes (ref. 5). The advantage of this method is that even rough values for $K$ can lead to quite precise values for $\Delta G^{\Theta}$ (an uncertainty of $\pm 10 \%$ in $K$ corresponds to $\pm 0.24 \mathrm{~kJ}$ $\mathrm{mol}^{-1}$ in $\Delta G^{\Theta}$ at $298 \mathrm{~K}$; an uncertainty usually beyond the capability of calorimetry). If a reliable (third law) value of $\Delta S^{\theta}$ is available this small uncertainty transfers to $\Delta H^{\Theta}$. This approach was used to obtain the enthalpy changes for catalysed disproportionation equilibria involving methylsilanes. These results were then combined with known values for $\Delta H_{\mathrm{f}}^{\Theta}\left(\mathrm{SiH}_{4}\right)$ and $\Delta H_{\mathrm{f}}^{\Theta}\left(\mathrm{Me}_{4} \mathrm{Si}\right)$ to obtain $\Delta H_{\mathrm{f}}^{\ominus}$ for the other (three) methylsilanes (ref.5).

Disproportionation enthalpies are themselves both interesting and revealing. Our data on the methylsilanes (Table 1) are compared with estimates for the chloro- and fluoro-silanes based on evaluated (ref. 6) or experimental values (ref. 7) for $\Delta H_{f}^{\ominus}$. The relatively small $\Delta H^{\ominus}$ values for the methyl- and chloro-silane reactions indicate that $\mathrm{X}-\mathrm{for}-\mathrm{H}$ substitution

TABLE 1. Disproportionation enthalpies for substituted silanes in $\mathrm{kJ} \mathrm{mol}^{-1}$ (298 $\left.\mathrm{K}\right)$

\begin{tabular}{|c|c|c|c|c|c|c|c|}
\hline \multicolumn{4}{|c|}{ Reaction } & & \multirow{2}{*}{$\frac{\mathrm{Me}^{\mathrm{a}}}{-2.1}$} & \multirow{2}{*}{$\frac{c^{\mathrm{C}}{ }^{\mathrm{b}}}{-9.6}$} & \multirow{2}{*}{$\begin{array}{r}F^{C} \\
+61.9\end{array}$} \\
\hline $2 \mathrm{XSiH}_{3}$ & $\Longrightarrow$ & $\mathrm{SiH}_{4}$ & $+\mathrm{X}_{2} \mathrm{SiH}_{2}$ & & & & \\
\hline $2 \mathrm{X}_{2} \mathrm{SiH}_{2}$ & $\Longrightarrow$ & $\mathrm{XSiH}_{3}$ & $+\mathrm{X}_{3} \mathrm{SiH}$ & & -3.2 & -4.6 & -33.5 \\
\hline $2 \mathrm{X}_{3} \mathrm{SiH}$ & $\rightleftharpoons$ & $\mathrm{X}_{2} \mathrm{SiH}_{2}$ & $+\mathrm{X}_{4} \mathrm{Si}$ & & -1.1 & +10.5 & +32.6 \\
\hline
\end{tabular}


produces an approximately constant effect. This is equivalent to constancy of bond enthalpy contributions (bond additivity). While the data for fluorosilanes might well be expected to show some deviations from bond additivity (i.e. non-negligible bond-interaction terms) the apparently large and alternating disproportionation values seem excessive and unreasonable (ref. 6). This suggests that there may be some errors in fluorosilane heats of formation (ref. 7). These could therefore usefully bear re-measurement.

\section{KINETIC MEASUREMENTS}

Two types of investigation have been carried out. One is concerned with the measurement of bond dissociation enthalpies using a kinetic iodination technique (ref. 4) and the other involves a method of measuring rates of silylene reactions (ref. 8), which, combined with pyrolytic information yields silylene heats of formation.

\section{Gas phase iodination kinetics}

The technique has been described in detail (ref. 4) and so only an outline is given here. The basis of the method involves study of the iodine abstraction process

$$
\mathrm{I}+\mathrm{RH} \rightleftharpoons \mathrm{R}^{\cdot}+\mathrm{HI}
$$

$E_{1}$ the activation energy of step (1) is measured directly and $E_{2}$ (believed smal1) is estimated. The justification for estimation is based on the proposition that small errors in $E_{2}$ lead to only small errors in $\Delta H^{\theta}$. Conditions of measurement are always such that the desired elementary process can be isolated and a thermal (Boltzmann) distribution of energy pertains. Once $\Delta H_{1}^{\Theta} \cdot 2$ is known it can be used, after correction to $298 \mathrm{~K}$ either to obtain $\Delta H_{\mathrm{f}}^{\Theta}$ for the radical $\mathrm{R}^{\cdot}$ (provided $\Delta H_{\mathrm{f}}^{\Theta}(\mathrm{RH})$ is known) or the bond dissociation enthalpy, $D(\mathrm{R}-\mathrm{H})$, via

$$
D(\mathrm{R}-\mathrm{H})=D(\mathrm{H}-\mathrm{I})+\Delta H_{1}^{\Theta}
$$

Recently we have used this method to obtain quantitative information on certain interactions in silicon-substituted alkyl radicals. The radicals concerned are shown in Fig. 1.
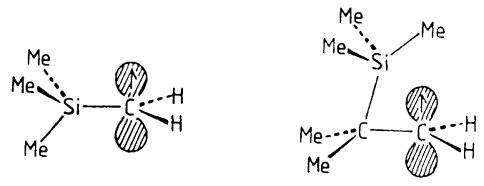

Fig. 1. $\alpha-$ and $\beta-$ silicon substituted alkyl radicals, generated via Iatom abstraction.
TABLE 2. Some Bond Dissociation Enthalpies in $\mathrm{kJ} \mathrm{mol}{ }^{-1}$

\begin{tabular}{lcrrc}
\hline \multicolumn{1}{c}{ Bond } & \multicolumn{2}{c}{$D(\mathrm{R}-\mathrm{H})$} & b & Reference \\
\hline $\mathrm{Me}_{3} \mathrm{CCH}_{2}-\mathrm{H}$ & & 417 & 11 \\
$\mathrm{Me}_{3} \mathrm{SiCH}_{2}-\mathrm{H}$ & $415 \pm 5$ & 415 & 11 \\
$\mathrm{Me}_{3} \mathrm{SiCMe}_{2} \mathrm{CH}_{2}-\mathrm{H}$ & $410 \pm 11$ & 405 & 12 \\
\hline
\end{tabular}

\footnotetext{
a Based on $E_{1}$ only.

b Based on a collision theory $A$ factor estimate
}

There is plenty of evidence for the existence of $\alpha$ - and $\beta$ - interactions (ref. 9,10) and their magnitudes may be assessed by comparison of $\mathrm{C}-\mathrm{H}$ dissociation energies in the appropriate molecules with a suitable reference value. The measured data are shown in Table 2 . To reduce scatter in the results the measured rate constants are fitted to an $A$ factor estimated via collision theory which is known to fit other iodine atom abstraction processes quite well (based on data from studies cited in ref. 4). Such a procedure is the kinetic equivalent of the so-called "third 1aw" method of obtained enthalpy changes from equilibrium constants in Thermodynamic experiments. Thus provided the neopentyl radical, $\mathrm{Me}_{3} \mathrm{CC}_{2}$, is accepted as a reference with no special interaction, then the $\alpha$-silicon stabilisation (in $\mathrm{Me}_{3} \mathrm{SiC}_{2}$ ) is $c a 2 \mathrm{~kJ} \mathrm{~mol}^{-1}$ while the $\beta$-silicon stabilisation (in $\mathrm{Me}_{3} \mathrm{SiCMe}_{2} \dot{\mathrm{CH}}_{2}$ ) is $c a$ $12 \mathrm{~kJ} \mathrm{~mol}^{-1}$. Thus, as foreshadowed (ref. 4), $\beta$-stabilisation is the more substantial. The origin of this effect is discussed elsewhere (ref. 12). The magnitude of $\beta$-substituent effects for elements other than silicon is not known but clearly they are likely to be of great importance for organometallic free radical chemistry in general.

\section{Gas phase silylene insertion kinetics}

Silylenes, $\mathrm{SiX}_{2}$, are known to be substantially stabilised by an $s^{2}$ lone pair effect (ref.4, 6). The establishment of stabilisation energies, and their influence by substituents (X) depends, in part, on a knowledge of $\Delta H_{\mathrm{f}}^{\theta}\left(\mathrm{SiX}_{2}\right)$. An important general source of such data are kinetic studies on the decomposition reactions

$$
\mathrm{YSiX}_{3}=\mathrm{XY}+\operatorname{SiX}_{2}
$$

and their reverse reactions, the $\mathrm{SiX}_{2}$ insertion processes. Many pyrolytic studies, of silicon compounds, particularly of disilanes, have been carried out by the groups of Purnel1, Davidson and Ring \& O'Neal. Some of these are cited in our own recent work (ref. 13) on $\mathrm{Si}_{2} \mathrm{~F}_{6}$ pyrolysis. A11 these studies give values for $\mathrm{E}_{3}$, the activation energy for 
decomposition of a particular silane (or disilane). If thermodynamic data, such as $\Delta H_{\mathrm{f}}^{\Theta}\left(\mathrm{SiX}_{2}\right)$ are required, however, not only do the enthalpies of formation of the other species need to be known but also $E_{4}$, the $\mathrm{SiX}_{2}$ insertion barrier. Until recently experimental values for such barriers were unknown and could only be estimated approximately. In the past two years, however, a number of direct, time-resolved rate studies have appeared for $\mathrm{SiCl}_{2}$ (ref. 14), $\mathrm{SiF}_{2}$ (ref. 15) and $\mathrm{SiH}_{2}$ (ref. 16,17) in the gas phase and $\mathrm{SiMe}_{2}$ (ref. 18) and SiMePh (ref. 19) in solution. We have used the data for $\mathrm{SiMe}_{2}$ to estimate a barrier for the insertion process

$$
\mathrm{Me}_{2} \mathrm{Si}+\mathrm{Me}_{3} \mathrm{SiH} \longrightarrow \mathrm{Me}_{3} \mathrm{SiSiMe}_{2} \mathrm{H}
$$

and thereby derived $\Delta H_{\mathrm{f}}^{\Theta}\left(\mathrm{SiMe}_{2}\right)$ (vide infra and ref. 20). This ought to give an improved value over earlier estimates but it should be borne in mind that the direct study of $\mathrm{SiMe}_{2}$ was carried out in solution (cyclopentane). A confirmatory gas phase study is highly desirable to rule out the possible complication of solvation effects.

The direct gas phase work on $\mathrm{SiCl}_{2}$ and $\mathrm{SiF}_{2}$ does not yet offer any example of a reaction which may be usefully exploited to obtain enthalpies of formation (which are anyway available from equilibrium studies (ref. 6)). However, the work on $\mathrm{SiH}_{2}$ has provided both new data and a lively controversy. Using time-resolved laser absorption, Jasinski (ref. 17) obtained a rate constant $(298 \mathrm{~K})$ of $1.6 \times 10^{9} \mathrm{dm}^{3} \mathrm{~mol}^{-1} \mathrm{~s}^{-1}$ for the reaction of $\mathrm{SiH}_{2}$ with $\mathrm{D}_{2}$. The choice of $\mathrm{D}_{2}$ rather than $\mathrm{H}_{2}$ was to minimize reverse decomposition to $\mathrm{SiH}_{2}$ of vibrationallyexcited (unstabilised) $\mathrm{SiH}_{2} \mathrm{D}_{2}$. Thus Jasinski was able to argue that his rate constant represented, to a close approximation, that for

$$
\mathrm{SiH}_{2}+\mathrm{H}_{2} \longrightarrow \mathrm{SiH}_{4}
$$

Jasinski argued that his result supported an upward revision of $\Delta H_{\mathrm{f}}^{\ominus}\left(\mathrm{SiH}_{2}\right)$ from an oft-quoted value of $243 \mathrm{~kJ} \mathrm{~mol}^{1}$ (ref. 4) close to a figure of $285 \mathrm{~kJ} \mathrm{~mol}^{-1}$ obtained by theoretical calculation (ref. 21). The earlier figure for $\Delta H_{\mathrm{f}}^{\Theta}\left(\mathrm{SiH}_{2}\right)$ was based on an estimate for $\mathrm{k}_{6}$ which was ca $10^{4}$ lower than that recently measured.

We (ref. 22) have investigated this system using the photodecomposition of phenylsilane $\left(\lambda=206 \mathrm{~nm}, T=100{ }^{\circ} \mathrm{C}\right.$ ) as a source of $\mathrm{SiH}_{2}$ and a competitive technique (ref. 8) in which rates of reaction of $\mathrm{SiH}_{2}$ are measured relative to that for

$$
\mathrm{SiH}_{2}+\mathrm{C}_{6} \mathrm{H}_{5} \mathrm{SiH}_{3} \rightarrow \mathrm{C}_{6} \mathrm{H}_{5} \mathrm{Si}_{2} \mathrm{H}_{5}
$$

Reaction (6) was studied over a pressure range and found, as expected, to be pressure dependent (i.e. not strictly second order). This is an indication of a non-Boltzmann distribution of energized $\mathrm{SiH}_{4}$ molecules. By means of theoretical (RP.KM) modelling we were able to establish that $k_{6}^{\infty} / k_{7}$ was 0.017 (to within a factor of 2 ) where $k_{6}^{\infty}$ represents the limiting (second order) rate constant (thermalized energy distribution). The absolute rate constant for $k_{7}$ was established via our relative rate studies (ref. 8) and direct measurements of Inoue and Suzuki (ref. 16). This led to $k_{6}^{\infty}(373 \mathrm{~K})=1.1 \times 10^{9} \mathrm{dm}^{3} \mathrm{~mol}^{-1} \mathrm{~s}^{-1}$, in satisfactory agreement with Jasinski's value at $298 \mathrm{~K}$ for a fast reaction with little or no activation energy.

Because of uncertainties in our value, and the lack of a measured activation energy $\left(E_{6}\right)$ we adopted a third law approach to the calculation of $\Delta H_{6}{ }_{6},-6(298 \mathrm{~K})$. The SiH $H_{4}$ decomposition rate constant $\left(k_{-6}\right)$ was calculated from the known Arrhenius equation (ref. 23 ) and combined with Jasinski's value for $k_{6}$ to give, $K_{6},-6=7.0 \times 10^{34} \mathrm{~atm}^{-1}$ and $\Delta G_{6}^{\Theta},-6=-199 \mathrm{~kJ} \mathrm{~mol}^{-1}$. From tabulated entropies we obtained $\Delta S_{6,-6}^{\Theta^{6}}=-133 \mathrm{JK}^{-1} \mathrm{~mol}^{-1}$ and thereby $\Delta H_{6}^{\ominus},-6=$ $-238 \mathrm{~kJ} \mathrm{~mol}^{-1}$. Taken in conjunction with $\Delta H_{\mathrm{f}}^{\Theta}\left(\mathrm{SiH}_{4}\right)$ (ref. 24) this yields $\Delta H_{\mathrm{f}}^{\Theta}\left(\mathrm{SiH}_{2}\right)=$
$273 \mathrm{~kJ} \mathrm{~mol}^{-1}$ with an uncertainty estimated to be no more than $\pm 6 \mathrm{~kJ} \mathrm{~mol}^{-1}$.

This value lies closer to recent theoretical calculations (ref. 21) than the older estimated figure and must be regarded as more reliable. It is essentially equivalent to Jasinski's estimate (ref. 17) and close to another experimental figure of $289( \pm 12) \mathrm{kJ} \mathrm{mol}^{-1}$ obtained by Shin and Beauchamp (ref. 25) by measurements of the gaseous proton affinity of $\mathrm{SiH}_{2}$.

The previous value of $\Delta H_{\mathrm{f}}^{\Theta}\left(\mathrm{SiH}_{2}\right)$ was based on arguments (ref. 26) concerning the reaction

$$
\mathrm{Si}_{2} \mathrm{H}_{6} \quad \rightleftarrows \mathrm{SiH}_{4}+\mathrm{SiH}_{2}
$$

We have been able to show (ref. 22) that the revised value of $273 \mathrm{~kJ} \mathrm{mo1^{-1 }}$ for $\Delta H_{\mathrm{f}}^{\Theta}\left(\mathrm{SiH}_{2}\right)$ is consistent with the forward and reverse rate constants in an absolute (third law) $\mathrm{f}_{\text {sense at }}$ $585 \mathrm{~K}$ provided the new directly measured $k_{9}$ is used (ref. 16). The data can also be reconciled with higher temperature, shock tube measurements of $\mathrm{Si}_{2} \mathrm{H}_{6}$ pyrolysis (ref. 27) provided careful account is taken of unimolecular fall-off effects (non-Boltzmann internal energy distribution of internal states). There are still some apparent difficulties over the Arrhenius parametersfor reaction (8), but there is no longer data for this system which 
is in complete conflict with the new $\Delta H_{f}^{\ominus}\left(\mathrm{SiH}_{2}\right)$. The lesson is that provided careful measurements are made of both forward and reverse reactions, provided due account is taken of non-Boltzmann (unimolecular fall-off) effects, and provided ancillary $\Delta H_{f}^{\ominus}$ data is available, such kinetic systems yield useful data on $\Delta H_{\mathrm{f}}^{\Theta}$ for reactive intermediates.

A summary of present thermodynamic data on divalent silicon (silylene) species is provided in Table 3 .

TABLE 3. Thermodynamic data for silylenes

\begin{tabular}{lrr}
\hline Species & \multicolumn{1}{c}{$\Delta H_{\mathrm{f}}^{\Theta} / \mathrm{kJ} \mathrm{mo1}^{-1}$} & DSSE \\
\hline $\mathrm{SiH}_{2}$ & $273 \pm 6$ & $81 \pm 9$ \\
$\mathrm{SiMe}_{2}$ & $92 \pm 8$ & $134 \pm 12$ \\
$\mathrm{SiF}_{2}$ & $-590 \pm 8$ & $205 \pm 42$ \\
$\mathrm{SiCl}_{2}$ & $-169 \pm 3$ & $159 \pm 17$ \\
$\mathrm{SiBr}_{2}$ & $-46 \pm 8$ & $142 \pm 50$ \\
$\mathrm{SiI}_{2}$ & $92 \pm 8$ & $134 \pm 54$
\end{tabular}

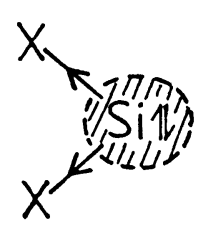

As well as heat of formation data this also shows the divalent state stabilisation energy (DSSE) operationally defined as the difference between first and second dissociation enthalpies in any $\mathrm{SiX}_{4}$ species. This is obtained from existing data (ref. 4, 6, 20) and the new $\Delta H_{\mathrm{f}}\left(\mathrm{SiH}_{2}\right)$. The figures lend support to the idea (ref:6) that DSSE depends on the electronegativity of the substituent since clearly there is a correlation. This may be understood in terms of a deshielding effect (Fig. 2). The more electronegative the substituent the more the bonding electrons are attracted further from the silicon nucleus, thus increasing the attraction of the nucleus for the (largely s-type) 1one-pair electrons

The author acknowledges support of the U.K. S.E.R.C. over a number of years.

\section{REFERENCES}

1. D.R.Stu11, E.F. Westrum Jr., and G.C. Sinke, The Chemical Thermodynamics of Organic Compounds, Wiley, New York (1969).

2. J.D. Cox and G. Pilcher, Thermochemistry of Organic and Organometallic Compounds, Academic Press, London (1970).

3. J.W. Moore and R.G. Pearson, Kinetics and Mechanism, p.307, Wiley, New York (1981).

4. R. Walsh, Acc. Chem. Res., 14, 246-252 (1981).

5. A.M. Doncaster and R. Walsh, J. Chem. Soc., Faraday Trans. 2, 82, 707-717 (1986).

6. R. Walsh, J. Chem. Soc., Faraday Trans. 1, 79, 2233-2248 (1983).

7. M. Farber and R. Srivastava, Chem. Phys. Lett., 51, 307-310 (1977).

8. C.D. Eley, M.C.A. Rowe and R. Walsh, Chem. Phys. Lett., 126, 153-157 (1986).

9. T. Kawamura and J.K. Kochi, J. Am. Chem. Soc., 94, 648-650 (1972).

10. R.A. Jackson, K.U. Ingold, D. Griller and A.S. Nazran, J. Am. Chem. Soc., 107, 208-211 (1985).

11. A.M. Doncaster and R. Walsh, J. Chem. Soc., Faraday Trans.1, 72, 2908-2916 (1976).

12. N. Auner, R. Walsh and J. Westrup, J. Chem. Soc., Chem. Commun., 207-208 (1986).

13. S.K. Bains, P.N. Noble and R. Walsh, J. Chem. Soc., Faraday Trans. 2, 82, 837-847 (1986).

14. I. Safarik, B.P. Ruzsicska, A. Jodhan, O.P. Strausz and T.N. Be11, Chem. Phys. Lett., 113, 71-74 (1985).

15. A.C . Stanton, A. Freeman, J. Wormhoudt and P.P. Gaspar, Chem. Phys. Lett., 122, 190-195 (1985).

16. G. Inoue and M. Suzuki, Chem. Phys. Lett., 122, 361-364 (1985).

17. J.M. Jasinski, J. Phys. Chem., 90, 555-557 (1986).

18. A.S. Nazran, J.A. Hawari, D. Griller, I.S. Alnaimi and W.P. Weber, J. Am. Chem. Soc., 106, 7267-7268 (1984).

19. P.P. Gaspar, B.H. Boo, S. Chari, A.K. Ghosh, D. Holten, C. Kirmaier and S. Konieczny, Chem. Phys. Lett., 105, 153-157 (1984).

20. R. Walsh, J. Phys. Chem., 90, 389-394 (1986).

21. P. Ho, M.E. Coltrin, J.S. Binkley and C.F. Melius, J. Phys. Chem., 89, 4647-4654 (1985).

22. H.M. Frey, R. Walsh and I.M. Watts, J. Chem. Soc., Chem. Commun., accepted for publication (1986).

23. J.W. Erwin, M.A. Ring and H.E. O'Neal, Int. J. Chem. Kinet., 17, 1067-1083 (1985).

24. JANAF Thermochemical Tables, 1978 Supplement, J. Phys. Chem. Ref. Data, 7 , 793-940 (1978).

25. S.K. Shin and J.L. Beauchamp, J. Phys. Chem., 90, 1507-1509 (1986).

26. P. John and J.H. Purne11, J. Chem. Soc., Faraday Trans. 1, 69, 1455-1461 (1973).

27. J. Dzarnoski, S.F. Rickborn, H.E. O'Neal and M.A. Ring, Organometallics, 1, 1217-1220 (1982). 